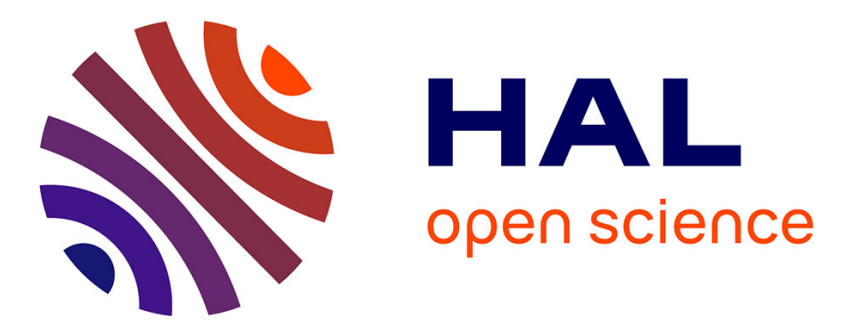

\title{
A Centronuclear Myopathy - Dynamin 2 Mutation Impairs Autophagy in Mice
}

Anne-Cécile Durieux, Stéphane Vassilopoulos, Jeanne Lainé, Bodvael Fraysse, Laura Briñas, Bernard Prudhon, Josiane Castells, Damien Freyssenet, Gisele Bonne, Pascale Guicheney, et al.

\section{To cite this version:}

Anne-Cécile Durieux, Stéphane Vassilopoulos, Jeanne Lainé, Bodvael Fraysse, Laura Briñas, et al.. A Centronuclear Myopathy - Dynamin 2 Mutation Impairs Autophagy in Mice. Traffic, 2012, 13 (6), pp.869-879. 10.1111/j.1600-0854.2012.01348.x . hal-02453822

\section{HAL Id: hal-02453822 \\ https://hal.science/hal-02453822}

Submitted on 24 Jan 2020

HAL is a multi-disciplinary open access archive for the deposit and dissemination of scientific research documents, whether they are published or not. The documents may come from teaching and research institutions in France or abroad, or from public or private research centers.
L'archive ouverte pluridisciplinaire HAL, est destinée au dépôt et à la diffusion de documents scientifiques de niveau recherche, publiés ou non, émanant des établissements d'enseignement et de recherche français ou étrangers, des laboratoires publics ou privés. 


\title{
A centronuclear myopathy-dynamin 2 mutation impairs autophagy in mice
}

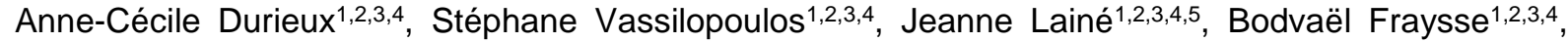 \\ Laura Briñas ${ }^{1,2,3,4}$, Bernard Prudhon ${ }^{1,2,3,4}$, Josiane Castells ${ }^{6}$, Damien Freyssenet ${ }^{6}$, Gisèle Bonne B $^{1,2,3,4,7}$, \\ Pascale Guicheney ${ }^{8}$, Marc Bitoun ${ }^{1,2,3,4}$. \\ 1 Université Pierre et Marie Curie-Paris 6, UM76, Paris, F-75013, France. ${ }^{2}$ Inserm, U974, Paris, F-75013, France. \\ ${ }^{3}$ CNRS, UMR 7215, Paris, France. ${ }^{4}$ Institut de Myologie, Paris, France. ${ }^{5}$ Université Pierre et Marie Curie-Paris \\ 6, Département de Physiologie, site Pitié-Salpêtrière, Paris, F-75013, France. ${ }^{6}$ Laboratoire de Physiologie de \\ I'Exercice, EA4338, Saint Etienne, France. ${ }^{7}$ AP-HP, Groupe Hospitalier Pitié-Salpêtrière, U.F. Cardiogénétique et \\ Myogénétique, Service de Biochimie Métabolique, Paris, F-75013, France. ${ }^{8}$ Inserm, U956, Paris, F-75013, \\ France.
}

\author{
Corresponding Author: \\ Marc Bitoun \\ Inserm U974, Institut de Myologie, Paris, France. \\ e-mail:m.bitoun@institut-myologie.org \\ Tel: 33 (0) 1.42.16.57.18 \\ Fax: 33 (0) 1.42.16.57.00
}

Keywords:

Dynamin 2, Autophagosome maturation, Knock-In mouse model, Neonatal Autophagy.

Running title:

Dynamin 2 mutation impairs autophagy

Dynamin 2 (Dnm2) is involved in endocytosis and intracellular membrane trafficking through its function in vesicle formation from distinct membrane compartments. Heterozygous mutations in the DNM2 gene cause dominant centronuclear myopathy or Charcot-Marie-Tooth neuropathy. We generated a knock-in $\mathrm{KI}-D n m 2^{\mathrm{R} 465 \mathrm{~W}}$ mouse model expressing the most frequent human mutation and recently reported that heterozygous mice progressively developed a myopathy. We investigated here the cause of neonatal lethality occurring in homozygous mice. We show that homozygous mice present at birth with a reduced body weight, hypoglycemia, increased liver glycogen content and hepatomegaly, in agreement with a defect in neonatal autophagy. In vitro studies performed in homozygous embryonic fibroblasts point out to a decrease in the autophagy flux prior to degradation at the autolysosome. We show that starved homozygous cells have a higher number of autophagy-related structures which remain in immature stages probably due to a defect of acidification. Our results highlight the role of Dnm2 in the crosstalk between endosomal and autophagic pathways and evidence a new role of Dnm2-dependent membrane trafficking in autophagy which may be relevant in DNM2-related human diseases.

Macroautophagy (hereafter called autophagy) is an ubiquitous catabolic pathway in which cytoplasmic proteins and organelles are sequestered in a double membrane vesicle called autophagosome and subsequently hydrolysed in lysosomes (1). Autophagy is involved in cytoplasmic component turnover and in cellular response to starvation especially during the neonatal starvation period resulting from interruption of trans-placental nutrient supply (2). Formation, maturation, migration and final fusion of autophagosomes with lysosomes are tightly regulated by more than 30 autophagy-related genes (ATG) (3). The origin of membranes necessary for autophagosome formation is not clearly defined but studies have involved endoplasmic reticulum, Golgi apparatus, mitochondria and plasma membrane (4-7). Afterwards, autophagosomes undergo a maturation process from immature autophagic vacuoles to degradative autophagic vacuoles. All along their maturation, fusion events occur between autophagic vacuoles and components of the endosomal system (early and late endosomes, and lysosomes) providing hydrolytic enzymes to autophagosomes (8). In addition, autophagosome maturation and movement require the microtubule network $(9,10)$.

To better understand the pathophysiological mechanisms of the dynamin 2 (Dnm2)-related autosomal dominant centronuclear myopathy (CNM), we generated a Knock-In (KI) mouse model expressing a CNM-DNM2 point mutation (p.R465W). Heterozygous mice are viable and progressively develop a myopathy sharing several similarities with the human disease (11). However, homozygous (HMZ) mice die at birth without evident morphological abnormalities but their body weight was 15\% lower than wild-type (WT), similarly to the Atg5- and Atg7-knock out models $(12,13)$.

Dnm2 is a ubiquitously expressed large GTPase, involved in various membrane trafficking events (14). GTP hydrolysis is associated with the release of nascent vesicles from the plasma membrane $(15,16)$ and from intracellular compartments, including the endosomal system and the Golgi apparatus (17-19). Moreover, several studies have demonstrated that Dnm2 directly interacts with the microtubule and actin cytoskeleton networks (14). 
The neonatal lethality of the HMZ KI-Dnm2 $2^{\mathrm{R} 45 \mathrm{~W}}$ mice combined to the known functions of Dnm2 in the endosomal pathway, intracellular membrane trafficking and microtubule network regulation argue for a possible role of Dnm2dependent processes in autophagy. We report that autophagy is impaired in HMZ mice, and by using embryonic

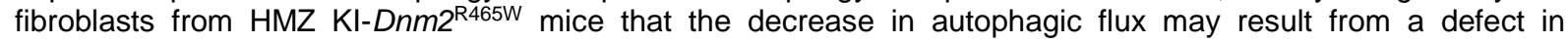
autophagosome maturation.

\section{Results}

\section{Neonatal lethality in HMZ mice is associated with hypoglycemia and hepatomegaly}

HMZ embryos did not show detectable developmental defects as evidenced by histological analysis (data not shown) and neonates present with normal motility and morphology at birth (Figure 1A). Nevertheless, HMZ neonates were 15\% lighter than their wild-type (WT) and heterozygous (HTZ) littermates (Figure 1B). The weight of most organs including brain, heart, kidney, lung and diaphragm normalized to the total body weight was unchanged (Supplementary Figure 1) except for liver whose weight was significantly increased both in HTZ (43.6 $\pm 1.2 \mathrm{mg} / \mathrm{g})$ and HMZ $(49.8 \pm 1.6 \mathrm{mg} / \mathrm{g})$ mice by comparison to WT mice $(39.4 \pm 0.9 \mathrm{mg} / \mathrm{g})$ (Figure 1C). The HMZ mice die within 24 hours after birth similarly to autophagy deficient mouse models $(12,13)$ where pups are unable to survive the neonatal starvation period. In agreement with a deficient nutrient supply, HMZ neonates displayed hypoglycemia (Figure 1D). Altogether, these results suggest that Dnm2 is required for survival during the neonatal starvation period and suggest that Dnm2 mutation could cause liver dysfunction in HMZ mice.

\section{Histology and glycogen content are altered in HMZ liver}

At late embryonic stages, no change in liver histology was evidenced in HMZ mice (Supplementary Figure 2). However, after birth, histological analysis revealed disorganized structures with cell enlargement (Figure $2 \mathrm{~A}$, top panel). Given the role of the liver in glycogenolysis to counteract neonatal hypoglycemia in part through autophagy, glycogen content was assessed by histochemical staining. Periodic acid Schiff (PAS) staining displayed an increase in glycogen content in HMZ liver (Figure 2A, bottom panel), 5-fold higher than in WT mice (Figure 2B). In hindlimb muscles from neonates, the glycogen content is similar to WT (Supplementary Figure $3 A)$. In order to study the autophagic pathway, LC3 and p62 immunoblots were performed in liver protein extracts (Figure 2C and D). LC3 exists in two forms. Upon autophagosome formation, LC3-I is converted to LC3-II by conjugation to the lipid phosphatidylethanolamine, which remains located in the autophagosome until its degradation in the autolysosomes. Consequently, LC3-II was used as marker of autophagosome amount. The p62-linked ubiquitinated proteins are sequestered into autophagolysomes after p62 interaction with LC3. From this point of view, p62 is considered as a substrate of autophagy which is accumulated when autophagy is impaired. In HMZ liver, these two markers were slightly increased suggesting a higher number of autophagosomes. There is no change in HTZ liver (not shown) and in HTZ and HMZ hindlimb muscles (Supplementary Figure 3B) when compared to WT mice. To specify the possible alteration induced by the Dnm2 mutation, we performed an in vitro study using mouse embryonic fibroblasts (MEF) from KI-Dnm2 mice. Given the absence of phenotype in HTZ animals, we focused our study on the comparison of HMZ versus WT genotypes.

\section{Dnm2 expression level is up-regulated in starved MEF}

We measured the levels of autophagy-related gene transcripts in MEF cultured under basal conditions or after stimulating autophagy by starvation. Under basal conditions, there was no change in the transcript levels of the tested genes in HMZ cells when compared to WT cells except for the LC3 transcript which was significantly overexpressed (Figure 3A). After incubation for 2 hours in Hank's balanced salt solution (HBSS), LC3, Gabarapl1, and p62 exhibited a starvation-induced up-regulation in WT cells which was preserved in HMZ cells. Similarly, the Dnm2-mRNA expression was unchanged under basal conditions in HMZ and WT MEF and exhibited a starvationinduced upregulation. Dnm1, Dnm2 and Dnm3 are all expressed in MEF but only the Dnm2 transcript was upregulated by starvation, both in WT and HMZ cells (Figure 3A). At the protein level, Dnm2 was unchanged after a 2-hour starvation period (data not shown) but was increased after a 5-hour starvation (Figure 3B) in WT and HMZ fibroblasts.

\section{Autophagic pathway is impaired in HMZ MEF}

In order to assess the autophagy flux, expression level of LC3-II was determined in MEF treated or not with Bafilomycin A1 (Baf) which inhibits the lysosomal $\mathrm{Na}^{+} / \mathrm{H}^{+}$pump and then decreases the degradation of the autolysosome content. In WT MEF under basal conditions, Baf treatment induces a 4-fold increase in LC3 lipidation (Figure 4). In contrast, the Baf-induced increase in LC3-II content is significantly reduced in HMZ cells. Similarly in starved cells, the Baf-induced increase of LC3-II content is lower in HMZ cells when compared to WT cells (Figure 4). The number of p62-positive was determined in WT and HMZ cells. Similar to the LC3 lipidation, the Baf-induced increase of number of p62-positive bodies is lower in HMZ cells under basal conditions and after starvation when compared to WT cells (Figure 5). These results show a slowing down of the autophagic pathway in the HMZ cells due to a defect located prior to the degradation by autolysosomes. An intringuing finding is that the number of p62-positive bodies is higher in $\mathrm{HMZ}$ cells under basal conditions (Figure 5). This was confirmed by counting GFP-LC3-positive bodies after transfection and LC3-positive bodies by immunocytochemistry of endogenous LC3 (Supplementary Figure 4A-D). As elevated intracellular $\mathrm{Ca}^{2+}$ has been shown to induce autophagosome formation, we used the fura-2 $\mathrm{Ca}^{2+}$ probe to assess intracellular $\mathrm{Ca}^{2+}$ levels. We found a significant increase in basal cytosolic $\mathrm{Ca}^{2+}$ concentration in HMZ MEF when compared to WT cells $(86.3 \pm 3.3 \mathrm{nM}$ in WT vs $126.6 \pm 4.7 \mathrm{nM}$ in HMZ cells, $\mathrm{p}<0.001$ using Student $t$-test; $\mathrm{n}=532$ WT cells and $465 \mathrm{HMZ}$ cells from 5 
embryos per genotype). Altogether, these results show a higher number of autophagy-related structures (LC3 and p62-positive bodies) under basal conditions but associated with a decrease of the autophagic flux suggesting a defect in the autophagosome maturation.

Lysosomal cathepsin $\mathrm{B}+\mathrm{L}$ enzymatic activities, cathepsin $\mathrm{D} /$ pro-cathepsin $\mathrm{D}$ expression level and the endocytosis-induced EGF-receptor degradation, which is mediated by lysosomes, are similar in WT and HMZ cells (Supplementary Figure 5) under basal conditions suggesting functional lysosomal compartment. In addition, proteasome activity is normal, ubiquitinated protein content is unchanged and expression level of cyclin D, a proteasome substrate, is not affected (Supplementary Figure 5) showing that inhibition of the autophagylysosome pathway is not associated with proteasome impairment.

\section{The Dnm2 mutation induces a defect in autophagosome maturation}

Autophagosome maturation depends on its progressive luminal acidification resulting from the fusion with vesicles from the endosomal pathway. Acridine orange staining was used in order to determine the total area of the acidic compartments (Figure $6 \mathrm{~A}$ and $\mathrm{B}$ ). The total acidic compartment is unchanged in HMZ cells under basal conditions. A significant acidification occurred in WT cells submitted to 2-hour starvation. This result probably reflects acidification of the newly formed autophagosomes. Such a starvation-induced acidification was also measured in HMZ cells but at a significantly lower level when compared to WT cells. To confirm an impaired autophagosome acidification, we performed a double tag strategy using pDest-mCherry-EGFP-p62 vector (20). Given that EGFP is acid-labile and mCherry is acid-stable, this approach allowed us to visualize p62 in neutral (green and red dots) and acidic structures (red only). In order to focus on the acidified dots, we determined the ratio (mCherry-GFP)/mCherry positive dots (Figure 6C and D). In WT cells, approximately $40 \%$ of the fluorescent structures were acid under basal conditions and $60 \%$ after starvation. The ratio is similar in $\mathrm{HMZ}$ cells under basal conditions and was not significantly modified by starvation in HMZ cells. Altogether, our results show that the level of acidification does not follow the number of autophagy-related structures under basal conditions or after starvation in agreement with a maturation defect in HMZ cells where the supernumerary autophagy-related structures under basal conditions or those induced by starvation are not properly acidified.

Electron microscopy was performed in starved WT and HMZ MEF. In WT cells, both early and late autophagosomes were present. Early autophagosomes were identified as double or multiple membrane-bound vacuoles segregating intact cytoplasmic material (Figure 7A). In contrast, late autophagic vacuoles contained degraded cytoplasmic content with an increased electron density (Figure 7B). Intermediate early autophagosomes containing partially undegraded cytoplasmic material were sometimes evidenced in WT cells (Figure 7C). Early and late autophagosomes were also present in HMZ cells (Figure 7D) but a notable difference was the higher proportion of intermediate early autophagosomes. These contained intact cytoplasmic elements together with altered, electron-dense portions of their limiting membrane (Figure 7. $\mathrm{E}_{3}$ and $\mathrm{E}_{4}$ ) or electron dense membranous elements embedded within their undegraded content (Figure $7 \mathrm{E}_{1}$ and $\mathrm{E}_{2}$ ). We counted the intermediate early autophagosomes in starved WT and HMZ MEF. Intermediate autophagosomes were not frequently found in WT MEF $(9.4 \%$ of the early autophagosomes) but represents $66.6 \%$ of the early autophagosomes in HMZ cells (72 out of 108). This notable morphological finding also supports an autophagosome maturation defect in HMZ cells.

\section{Dnm2 sub-cellular localization is altered in HMZ MEF}

The p.R465W Dnm2 mutant was shown to form abnormally stable polymers in vitro (21). Plasma membrane, intracellular membranes and cytosolic fractions were separated to determine if the mutated Dnm2 is accumulated in a particular fraction in HMZ MEF. Dnm2 associated signal was quantified and normalized to GAPDH associated signal present in the 3 fractions. Immunoblots of Caveolin 1 (Cav1), present in membrane fractions, and of $\mathrm{Na}^{+} / \mathrm{K}^{+}$ATPase, a marker of plasma membrane, were used as quality control (Figure 8). We showed that Dnm2 is present in the 3 fractions in basal and starved cells from WT and HMZ animals (Figure 8A) and that Dnm2 content was increased in the intracellular membrane fraction of HMZ starved cells (Figure 8B).

Fasting in adult HTZ mice induced an increased autophagosome formation.

Whereas HMZ mice die at birth, HTZ mice are viable but progressively develop a myopathy. We assessed the consequences of autophagy stimulation by a 24-hour fasting in the Tibialis anterior muscle which is the primarily and prominently affected muscle in this mouse model (11). Fasting induced a $10 \%$ loss of body weight in WT and HTZ mice and blood glycemia is similar in WT $(119.9 \pm 1.7 \mathrm{mg} / \mathrm{dL})$ and HTZ mice $(116.7 \pm 1.7 \mathrm{mg} / \mathrm{dL})$. HTZ muscles are significantly atrophied (-20\% vs WT) at 6 months of age as previously reported (11). LC3 and p62 immunoblots were performed (Figure 9). Fasting leads to a significant increase in LC3-II expression level without affecting p62 expression (Figure 9A and B). LC3-II and p62 expression were unchanged in liver from the same animals (Supplementary Figure 6). Electron microscopy study revealed supernumerary vacuoles showing characteristic features of the autophagic-related structures in some HTZ muscle fibres when compared with affected WT fibers (Figure 9C-G). Altogether these results are in agreement with an impairment to achieve the complete autophagy process despite an exacerbated autophagosome formation in skeletal muscle from adult HTZ mice in response to fasting

\section{Discussion}


Autosomal dominant centronuclear myopathy (AD-CNM) is a rare congenital myopathy caused by heterozygous dynamin 2 (Dnm2) mutations (22). Heterozygous knock-in (KI) mice expressing the most frequent CNM-DNM2 mutation, i.e. $\mathrm{KI}-D n m 2^{\mathrm{R}} 465 \mathrm{~W}$, progressively develop a muscular phenotype (11). We investigated here the cause of the neonatal lethality affecting the homozygous mice and identified a defect of the autophagic pathway highlighting a novel Dnm2 function as a regulator of autophagy.

Several knock-out mouse models for proteins of autophagy, i.e. Atg5, Atg7, Atg9a and Atg16L1 $(12,13,23,24)$, die within 1 day of delivery showing the essential role of autophagy for survival during neonatal starvation. In addition, the liver-specific Atg7-knock-out adult mice exhibited hepatomegaly and hepatocyte hypertrophy (13). The HMZ KI-Dnm2 mice share several features with these models: i) no obvious histological abnormalities during embryonic development, ii) normal appearance at birth except a lower body weight, iii) rapid lethality within 1 day of delivery, and iv) energy metabolism defects evidenced by hypoglycemia at birth. We hypothesize that homozygous mice are not able to rescue the physiological neonatal hypoglycemia due to an autophagy pathway defect and die rapidly. Neonatal autophagy is not only involved in glycogen degradation (25) but also in the neonatal amino-acid production $(12,13)$, in the adaptation to cell metabolism changes and to the oxidative stress occurring at birth (2). Dnm2 is ubiquitously expressed and autophagy is an important catabolic pathway in almost all the tissues. Consequently, we can not exclude that an impairment of one or more of the autophagy associated functions in more than one tissue could be involved in the neonatal lethality of the HMZ KI-Dnm2 mice.

Due to neonatal lethality, we further characterized impairment of the autophagic pathway in mouse embryonic fibroblasts (MEF). LC3 immunoblot and number of p62-positive bodies after Bafilomycin A1 treatment show that HMZ cells harbour a decrease in the LC3 lipidation and in the net autophagy flux due to a defect prior to the degradation by autophagolysosomes. Autophagy is a highly regulated pathway at different steps (autophagosome formation, maturation, trafficking, and fusion with lysosomes for final degradation). Given the role of Dnm2 in the endosomal pathway (14) and the inhibition of the clathrin-mediated endocytosis previously reported in the HMZ MEF (11), we postulate an impairment of the crosstalk between autophagosomes and endosomes, a crucial step in the autophagosome maturation through hydrolytic enzyme delivery $(8,27)$. This crosstalk leads to phagosomes acidification following fusion with early endosomes $(\mathrm{pH} 6.1$ to 5.5), late endosomes $(\mathrm{pH} 5.5)$ and lysosomes $(\mathrm{pH}$ 4.7) $(28,29)$. Such impairment may explain that the level of acidification does not follow the number of autophagic-related structures in HMZ cells. Indeed, under basal conditions and after starvation the total area of acidic compartment (acridine orange staining) and the number of acidic autophagic structures (double tag strategy) is abnormally low compared to the expected acidification. In addition, ultrastructural analysis showed a higher proportion of intermediate early autophagosomes at the expense of mature phagosomes containing fully degraded material. Further studies will be necessary to determine impact of DNM2 mutation on the initial step of autophagosome formation and trafficking.

An intriguing finding is that the number of LC3- or p62-positive structures is higher under basal conditions in HMZ MEF compared to WT whereas we showed a decrease in the net flux of autophagy. We can hypothesize that the increased free calcium concentration which can stimulate autophagosome formation (26) and increase of LC3mRNA content lead to a novel basal steady state in homozygous cells characterized by a higher number of LC3and p62-positive structures. On the other hand, the supernumerary fraction of LC3 and p62 under basal conditions may be aggregated in structure not related to autophagy (protein aggregate or a membrane compartment) which remained to be determined.

Dnm2 may regulate autophagy via its function in the endosomal pathway as indicated above. However, several findings suggest a more direct function of Dnm2 in autophagy: i) similarly to autophagy-related proteins LC3 and Gabarapl1, expression of Dnm2 is up-regulated by starvation, and this up-regulation is specific of Dnm2 among the 3 dynamins expressed in MEF, and ii) Dnm2 was found in the ATG2 subnetwork as a partner of WIPI2 in a proteomic analysis of the autophagy interaction network in human cells (30). ATG2 network is involved in the last steps of autophagosome formation (3) and WIPI2 was found to act in LC3 recruitment and lipidation to the forming phagosome (31). In addition, we showed that the p.R465W Dnm2 mutant accumulates in an intracellular membrane compartment which remains to be determined. We can hypothesize that the p.R465W mutant affects WIPI2 function at the level of autophagy-related vesicles leading to the defect of LC3-II lididation and slowing down the autophagic pathway despite a higher number of LC3-positive bodies in HMZ cells under basal conditions.

It is classically considered that autophagy inhibition also induces impairment of protein degradation by the ubiquitin-proteasome system (32). Indeed, when autophagy is blocked, as it is the case in the KO mouse models for ATG proteins, p62 accumulates in aggregates with ubiquitinated-proteins and then avoids degradation because of impaired delivery to the proteasome (33). In our cellular model, the level of autophagy inhibition may does not reach the threshold required to impair ubiquitin-proteasome pathway since proteasome activities appear unaffected as well as overall ubiquitinated-protein cell content and cyclin D expression level. However, even if the pathway is not totally blocked in our HMZ model, incomplete autophagy may have a strong impact during the early post-natal period requiring a fully active autophagy necessary for surviving until maternal milk supplementation. 
In contrast to the neonatal lethality of the $\mathrm{HMZ} \mathrm{KI}-\mathrm{Dnm} 2^{\mathrm{R} 465 \mathrm{~W}}$ mice, $\mathrm{HTZ}$ animals are viable and progressively develop a myopathic phenotype. In muscles from adult HTZ mice, we recently reported that FOXO3a and Gabarapl1 are upregulated at 2 months of age suggesting that activation of autophagy can be involved in Dnm2induced atrophy (11). However, no abnormal autophagy-related structures were evidenced by electron microscopy at the same age or later and the LC3 transcript level was unchanged. Here we report for the first time that autophagic regulation is impaired in muscle from adult HTZ mice where autophagy was triggered by fasting. In the Tibialis anterior muscle, the primarily and prominently affected muscle in the KI-Dnm2 model (11), the increased LC3-II expression is associated with supernumerary autophagy-related structures showed by ultrastructural analysis after 24-hour fasting period. We can hypothesize that the regulation of the autophagic pathway is impaired in HTZ skeletal muscles and that this inability to correctly adapt autophagic level to external stimuli could participate to the pathophysiology of the Dnm2-related diseases. Considering the role played by autophagy in organelles turnover, such impairment may explain the abnormal accumulation of mitochondria previously reported in the HTZ mice (11). Interestingly, among the genes linked to the different forms of CNM in human, one of them, i.e. MTMR14, has already been linked to autophagy. Two MTMR14 variants have been described in two CNM patients (34) and, more recently, MTMR14 was shown to act as a negative regulator of autophagy $(35,36)$. One CNM-linked MTMR14 mutant was unable to down-regulate autophagy suggesting that excessive autophagy may contribute to the pathogenesis (35). Participation of autophagy in pathogenesis of

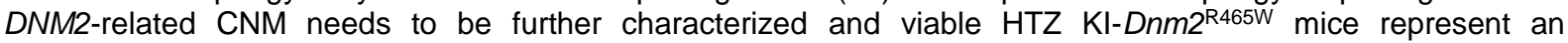
appropriate model in order to resolve this issue.

In conclusion, we showed that Dnm2 dysfunction induced by HMZ CNM-related mutation leads to an impairment of autophagy. Whereas crosstalk between endosomal and autophagosomal machineries has been recognized for a long time, our results demonstrate that Dnm2 participates in this crosstalk and may act as an autophagy regulator. Given the role played by autophagy in muscle homeostasis and in pathophysiological conditions, further studies are now necessary to evaluate the relevance of our results in the pathomechanisms occurring in the DNM2-related centronuclear myopathy or in other forms of neuromuscular disorders.

\section{Material and Methods}

\section{Production of KI-Dnm2 $2^{R 465 W}$ mice}

The dynamin 2 mutant C57BL/6 mouse line was established by homologous recombination using standard techniques (11). The wild-type (WT), heterozygous (HTZ) and homozygous (HMZ) neonates were obtained from heterozygous intercrosses. Genotyping was performed by PCR as previously described (11). Animal studies were performed in compliance with the French guidelines. Neonates were sacrificed by decapitation during the first day of life and tissue samples were snap frozen in liquid nitrogen for protein extraction or frozen in liquid nitrogencooled isopentane for histological analysis. Glycogen content was measured in liver and hindlimb muscles using the Glycogen Assay kit (Biovision) following manufacturer's instructions and blood glycemia was measured with an Accu-Chek apparatus (Roche diagnostics). Fasting in 6-month-old adult HTZ mice was done by 24-hour food deprivation. Thereafter, Tibialis anterior muscles and liver were snap frozen in liquid nitrogen for protein extraction and immunoblots or mice were transcardially perfused with $2 \%$ paraformaldehyde $2 \%$ glutaraldehyde in cold $0.1 \mathrm{M}$ phosphate buffer and Tibialis anterior were further processed as indicated for electron microscopy in embryonic fibroblasts.

\section{Mouse embryonic fibroblasts (MEF)}

MEF were prepared from 13.5 day-old embryos. Cells were cultured at $37^{\circ} \mathrm{C}\left(5 \% \mathrm{CO}_{2}\right)$ in Dulbecco's modified Eagle's medium (DMEM) containing $10 \%$ fetal calf serum (FCS) supplemented with penicillin, streptomycin, Lglutamate, and sodium pyruvate (basal medium). Starvation was induced by 2 or 5 hours incubation in Hank's balanced salt solution (HBSS, Invitrogen) without or with Bafilomycin A1 (100 nM) added 30 min before starvation. For EGF receptor degradation assay, MEF were incubated in FCS-free DMEM for 5 hours and media was then replaced by FCS-free medium containing $40 \mathrm{ng} / \mathrm{ml}$ EGF with or without bafilomycin A1.

For measurement of lysosome and proteasome activities, cells were lyzed in buffer $\mathrm{pH} 7.4$ containing Tris- $\mathrm{HCl} 50$ mM, NaCl 100 mM, EDTA 200 mM, EGTA 200 mM and Triton X100 1\%. Chymotrypsine-like enzyme activity of proteasome and cathepsin $B+L$ enzyme activity were fluorometrically determined $\left(\lambda_{\mathrm{exc}}=380 \mathrm{~nm}\right.$ and $\lambda_{\mathrm{em}}=460$ $\mathrm{nm}$ ) using succinyl-Leu-Leu-Val-Tyr-7-amido-4-methylcoumarin and benzyloxycarbonyl-Phe-Arg-amido-4methylcoumarin fluorogenic peptides (Bachem) as substrates as previously reported (37, 38). Acidic compartments were stained by $15 \mathrm{~min}$ incubation at $37^{\circ} \mathrm{C}$ with $1 \mu \mathrm{g} / \mathrm{ml}$ acridine orange in serum-free medium. Acridine orange-associated fluorescence was immediately imaged on live cells. The ratio of acidic compartment area/total cell area was quantified using Metamorph software. For transfection experiments, MEF were seeded in $35 \mathrm{~mm}$ diameter plates and transfected at 50\% confluency using polyethylenimine (PEI, Sigma-Aldrich). pDestmCherry-EGFP-LC3b $(2 \mu \mathrm{g})$ and pDest-mCherry-EGFP-p62 $(2 \mu \mathrm{g})(20)$ were mixed with $2 \mu \mathrm{l} \mathrm{PEI}(0.9 \mathrm{mg} / \mathrm{ml})$ for $30 \mathrm{~min}$ in $200 \mu \mathrm{LMEM}$ and then added to cells for 4 hours at $37^{\circ} \mathrm{C}$ in a final volume of $1 \mathrm{ml}$. This medium was then replaced by DMEM-10\% FCS for 2 days and submitted or not to 2 hours of starvation in HBSS and fixation in $4 \%$ paraformaldehyde for 15 min. Number of GFP-LC3- and GFP-p62-positive bodies was quantified using ImageJ software (NIH; http://rsbweb.nih.gov/ij) on a single focal plane acquired with a spectral confocal laserscanning microscope (SP2 AOBS; Leica). For live cell imaging, GFP and mCherry fluorescences were acquired on unfixed cells transfected with pDest-mCherry-EGFP-p62 using upright microscope (Axiophot2; Carl Zeiss) and number of GFP- and mCherry-positive bodies was quantified using ImageJ software. For the cytosolic $\left[\mathrm{Ca}^{2+}\right]$ 
measurements, MEF were loaded by exposure to $5 \mu \mathrm{M}$ of the $\mathrm{Ca}^{2+}$ fluorescent dye fura 2-AM (Invitrogen). Fura-2 fluorescence measurements were made with an integrated lonOptix device (lonOptix). The cytosolic [Ca $\left.{ }^{2+}\right]$ was calculated from ratiometric measurements according to a modified method from Grynkiewicz et al. (39, 40). For electron microscopy, MEF grown on Thermanox coverslips (Nunc) were starved for 2 hours and then fixed in $2.5 \%$ glutaraldehyde diluted in $0.1 \mathrm{M}$ phosphate buffer, $\mathrm{pH} 7.4$. They were further post-fixed in $2 \% \mathrm{OsO}_{4}$, gradually dehydrated in acetone including a $2 \%$ uranyl staining step in $70 \%$ acetone, and finally embedded in Epon resin (Electron Microscopy Sciences). After uranyl and lead citrate staining, ultrathin sections were examined with a Philips CM120 electron microscope and photographied with a SIS Morada digital camera.

\section{Subcellular fractionation}

MEF were homogenized in HES buffer at pH 7.4 (20 mM Tris- $\mathrm{HCl}, 1 \mathrm{mM}$ EDTA, $225 \mathrm{mM}$ sucrose) by passing 10 times through a 27-gauge needle. Homogenates were centrifuged at $19,000 \mathrm{~g}$ for $20 \mathrm{~min}$. The resulting pellets were resuspended in HES buffer, layered on top of a $1.12 \mathrm{M}$ sucrose cushion, and centrifuged at $101,000 \mathrm{~g}$ for 60 $\min$ at $4^{\circ} \mathrm{C}$. The plasma membrane fraction was collected from the interface of the 2 solutions. Centrifugation of the initial supernatant at $212,000 \mathrm{~g}$ for $60 \mathrm{~min}$ at $4^{\circ} \mathrm{C}$ allowed separation of the intracellular membrane fraction (pellet) and cytosol (supernatant). Cytosolic, plasma membrane and intracellular membrane fractions were submitted to western blot analysis using Dnm2 (Abcam, ab3457), GAPDH (Abcam, ab9485), Na/K ATPase (GeneTex, GTX30202) and Caveolin 1 (Santa Cruz, sc-894) antibodies.

\section{Total RNA extraction and cDNA analysis}

Total RNA from MEF was extracted using RNeasy fibrous tissue kit (Qiagen). Total RNA (500 ng) was submitted to reverse transcription (RT) using the Superscript II reverse transcriptase kit (Invitrogen). Quantification of Dnm2, LC3b, Gabarapl1, p62, and Atg4b transcripts was performed on a LightCycler480 System using the LighCycler480 SYBR Green I Master mix (Roche Applied Science). The program included an initial denaturation step of $10 \mathrm{~min}$ at $95^{\circ} \mathrm{C}$, followed by 40 amplification cycles of denaturation at $95^{\circ} \mathrm{C}$ for $15 \mathrm{sec}$, annealing at $62^{\circ} \mathrm{C}$ for $30 \mathrm{sec}$, and elongation at $72^{\circ} \mathrm{C}$ for $15 \mathrm{sec}$. For normalization purposes, amplification of the housekeeping gene encoding the acidic ribosomal phosphoprotein P0 (Arbp), was performed on the same plate. Data were analysed with the LightCycler480 software (Roche Applied Science). Sequences of primers are provided in supplementary Table 1.

\section{Protein extraction and western blot analysis}

Powdered frozen liver and MEF were lysed by sonication in lysis buffer $\mathrm{pH} 7.2$ containing $150 \mathrm{mM} \mathrm{NaCl}, 50 \mathrm{mM}$ Tris, $1 \mathrm{mM}$ EDTA, $0.1 \%$ Triton $\mathrm{X} 100,10 \%$ glycerol, $5 \mathrm{mM} \mathrm{MgCl} 2$ and $1 \%$ protease inhibitor cocktail (SigmaAldrich). Samples were centrifugated at $15,000 \mathrm{~g}$ at $4^{\circ} \mathrm{C}$ for $10 \mathrm{~min}$. Supernatant were collected and protein concentration was determined with the BCA Protein Assay kit (Thermo Scientific). The ubiquitinated protein immunoblots were performed on total cell lysate. Total proteins $(40 \mu \mathrm{g}$ for tissues and $20 \mu \mathrm{g}$ for MEF) were loaded on $15 \%$ SDS-PAGE for electrophoretic separation, transferred on polyvinylidene fluoride (PVDF) membrane for 3 $\mathrm{h}$ at $300 \mathrm{~mA}$ at $4^{\circ} \mathrm{C}$. Membranes were blocked for $1 \mathrm{~h}$ in PBS containing $5 \%$ non fat dry milk and $0.2 \%$ Tween20 before an overnight incubation with primary antibodies against Dnm2 (Abcam, ab3457, 1:400), LC3 (Cell Signaling, 2775, 1:1000), mono- and polyubiquitinated proteins (Enzo, clone FK2, 1:5000), cathepsin D (Abcam ab75852, 1:1000), cyclin D (Abcam, ab6152, 1:1000), EGFR (Cell Signaling 2232, 1:1000), actin (Sigma-Aldrich A2066, 1:2000) and GAPDH (Abcam ab9485, 1:1000). Incubation with horseradish peroxidase-conjugated antibodies (anti-goat, anti-mouse or anti-rabbit from Dako) was performed for chemiluminescence detection using the Supersignal West Pico Chemiluminescent kit (Pierce). Acquisition was performed on G-Box (Ozyme) and quantitative analyses were realized with GeneTools software (Syngene).

\section{Immunocytochemistry}

MEF were fixed $15 \mathrm{~min}$ at room temperature in 4\% paraformaldehyde. Non specific sites were blocked in PBS containing $2 \%$ horse serum, $0.5 \% \mathrm{lgG}$ free BSA and $0.1 \%$ Triton X-100 for $90 \mathrm{~min}$ and incubated overnight with the primary antibodies diluted in blocking buffer. Following antibodies were used: p62 (Abnova, clone 2C11, 1:400) and LC3 (Cell Signalling, 1:400), After washing, immunostaining was revealed by incubation for $2 \mathrm{~h}$ with AlexaFluor488- or AlexaFluor568-conjugated anti-rabbit or anti-mouse antibodies (Invitrogen) diluted at 1:400. Labelled MEF were mounted in Vectashield hard-set (Vector Laboratories) before imaging using a confocal Leica SP2 inverted microscope. LC3- and p62-positive dots were quantified using ImageJ software.

\section{Acknowledgements}

We thank T. Johansen for providing the LC3 and p62 plasmids and the Pitié-Salpêtrière Imaging Platform for confocal imaging acquisition facilities. This work was supported by the Institut National de la Santé et de la Recherche Médicale (INSERM), the Association Institut de Myologie (AIM), The Université Pierre et Marie CurieParis6 (UPMC, Emergence-2009 program) and the Centre National de la Recherche Scientifique (CNRS). AC Durieux and B Fraysse were recipients of AIM fellowships. LB was recipients of UPMC fellowship (Emergence2009 program).

\section{References}


1. Melendez A, Neufeld TP. The cell biology of autophagy in metazoans: a developing story. Development 2008;135:2347-2360.

2. Schiaffino S, Mammucari C, Sandri M. The role of autophagy in neonatal tissues: just a response to amino acid starvation? Autophagy 2008;4:727-730.

3. Xie Z, Klionsky DJ. Autophagosome formation: core machinery and adaptations. Nat Cell Biol 2007;9:11021109.

4. Mijaljica D, Prescott M, Devenish RJ. Endoplasmic reticulum and Golgi complex: Contributions to, and turnover by, autophagy. Traffic 2006;7:1590-1595.

5. van der Vaart A, Griffith J, Reggiori F. Exit from the Golgi Is Required for the Expansion of the Autophagosomal Phagophore in Yeast Saccharomyces cerevisiae. Mol Biol Cell 2010;21:2270-2284.

6. Hailey DW, Rambold AS, Satpute-Krishnan P, Mitra K, Sougrat R, Kim PK, Lippincott-Schwartz J. Mitochondria supply membranes for autophagosome biogenesis during starvation. Cell 2010;141:656-667.

7. Ravikumar B, Moreau K, Jahreiss L, Puri C, Rubinsztein DC. Plasma membrane contributes to the formation of pre-autophagosomal structures. Nat Cell Biol 2010;12:747-757.

8. Eskelinen EL. Maturation of autophagic vacuoles in Mammalian cells. Autophagy 2005;1:1-10.

9. Fass E, Shvets E, Degani I, Hirschberg K, Elazar Z. Microtubules support production of starvation-induced autophagosomes but not their targeting and fusion with lysosomes. J Biol Chem 2006;281:36303-36316.

10. Kochl R, Hu XW, Chan EY, Tooze SA. Microtubules facilitate autophagosome formation and fusion of autophagosomes with endosomes. Traffic 2006;7:129-145.

11. Durieux AC, Vignaud A, Prudhon B, Thao Viou M, Beuvin M, Vassilopoulos S, Fraysse B, Ferry A, Lainé J, Romero NB, Guicheney P, Bitoun M. A centronuclear myopathy-dynamin 2 mutation impairs skeletal muscle structure and function in mice. Hum Mol Genet 2010;19:4820-4836.

12. Kuma A, Hatano M, Matsui M, Yamamoto A, Nakaya H, Yoshimori T, Ohsumi Y, Tokuhisa T, Mizushima N. The role of autophagy during the early neonatal starvation period. Nature 2004;432:1032-1036.

13. Komatsu M, Waguri S, Ueno T, Iwata J, Murata S, Tanida I, Ezaki J, Mizushima N, Ohsumi Y, Uchiyama Y, Kominami E, Tanaka K, Chiba T. Impairment of starvation-induced and constitutive autophagy in Atg7-deficient mice. J Cell Biol 2005;169:425-434.

14. Durieux A, Prudhon B, Guicheney P, Bitoun M. Dynamin 2 and Human diseases. J Mol Med 2010;88:339350.

15. Warnock DE, Baba T, Schmid SL. Ubiquitously expressed dynamin-II has a higher intrinsic GTPase activity and a greater propensity for self-assembly than neuronal dynamin-I. Mol Biol Cell 1997;8:2553-2562.

16. Henley JR, Krueger EW, Oswald BJ, McNiven MA. Dynamin-mediated internalization of caveolae. J Cell Biol 1998;141:85-99.

17. van Dam EM, Stoorvogel W. Dynamin-dependent transferrin receptor recycling by endosome-derived clathrincoated vesicles. Mol Biol Cell 2002;13:169-182.

18. Nicoziani P, Vilhardt F, Llorente A, Hilout L, Courtoy PJ, Sandvig K, van Deurs B. Role for dynamin in late endosome dynamics and trafficking of the cation-independent mannose 6-phosphate receptor. Mol Biol Cell 2000;11:481-495.

19. Jones SM, Howell KE, Henley JR, Cao H, McNiven MA. Role of dynamin in the formation of transport vesicles from the trans-Golgi network. Science 1998;279:573-577.

20. Pankiv S, Clausen TH, Lamark T, Brech A, Bruun JA, Outzen H, Overvatn A, Bjorkoy G, Johansen T. p62/SQSTM1 binds directly to Atg8/LC3 to facilitate degradation of ubiquitinated protein aggregates by autophagy. J Biol Chem 2007;282:24131-24145.

21. Wang L, Barylko B, Byers C, Ross JA, Jameson DM, Albanesi JP. Dynamin 2 mutants linked to centronuclear myopathies form abnormally stable polymers. J Biol Chem 2010;285:22753-22757.

22. Bitoun $M$, Maugenre S, Jeannet PY, Lacène $E$, Ferrer X, Laforêt $P$, Martin JJ, Laporte J, Lochmuller $H$, Beggs $\mathrm{AH}$, Fardeau M, Eymard B, Romero NB, Guicheney P. Mutations in dynamin 2 cause dominant Centronuclear Myopathy. Nat Genet 2005;37:1207-1209.

23. Saitoh T, Fujita N, Hayashi T, Takahara K, Satoh T, Lee H, Matsunaga K, Kageyama S, Omori H, Noda T, Yamamoto N, Kawai T, Ishii K, Takeuchi O, Yoshimori T, et al. Atg9a controls dsDNA-driven dynamic translocation of STING and the innate immune response. Proc Natl Acad Sci U S A 2009;106:20842-20846.

24. Saitoh T, Fujita N, Jang MH, Uematsu S, Yang BG, Satoh T, Omori H, Noda T, Yamamoto N, Komatsu M, Tanaka K, Kawai T, Tsujimura T, Takeuchi O, Yoshimori T, et al. Loss of the autophagy protein Atg16L1 enhances endotoxin-induced IL-1beta production. Nature 2008;456:264-268.

25. Kotoulas OB, Kalamidas SA, Kondomerkos DJ. Glycogen autophagy in glucose homeostasis. Pathol Res Pract 2006;202:631-638.

26. Hoyer-Hansen M, Bastholm L, Szyniarowski P, Campanella M, Szabadkai G, Farkas T, Bianchi K, Fehrenbacher N, Elling F, Rizzuto R, Mathiasen IS, Jaattela M. Control of macroautophagy by calcium, calmodulin-dependent kinase kinase-beta, and Bcl-2. Mol Cell 2007;25:193-205.

27. Mehrpour M, Esclatine A, Beau I, Codogno P. Overview of macroautophagy regulation in mammalian cells. Cell Res 2010;20:748-762.

28. Zen K, Biwersi J, Periasamy N, Verkman AS. Second messengers regulate endosomal acidification in Swiss 3T3 fibroblasts. J Cell Biol 1992;119:99-110.

29. Kielian MC, Cohn ZA. Intralysosomal accumulation of polyanions. II. Polyanion internalization and its influence on lysosomal pH and membrane fluidity. J Cell Biol 1982;93:875-882.

30. Behrends C, Sowa ME, Gygi SP, Harper JW. Network organization of the human autophagy system. Nature 2010;466:68-76. 
31. Polson HE, de Lartigue J, Rigden DJ, Reedijk M, Urbe S, Clague MJ, Tooze SA. Mammalian Atg18 (WIPI2) localizes to omegasome-anchored phagophores and positively regulates LC3 lipidation. Autophagy 2010;6:506522.

32. Korolchuk VI, Menzies FM, Rubinsztein DC. Mechanisms of cross-talk between the ubiquitin-proteasome and autophagy-lysosome systems. FEBS Lett 2010;584:1393-1398.

33. Korolchuk VI, Mansilla A, Menzies FM, Rubinsztein DC. Autophagy inhibition compromises degradation of ubiquitin-proteasome pathway substrates. Mol Cell 2009;33:517-527.

34. Tosch V, Rohde HM, Tronchere H, Zanoteli E, Monroy N, Kretz C, Dondaine N, Payrastre B, Mandel JL, Laporte J. A novel Ptdlns3P and Ptdlns(3,5)P2 phosphatase with an inactivating variant in centronuclear myopathy. Hum Mol Genet 2006;15:3098-3106.

35. Vergne I, Roberts E, Elmaoued RA, Tosch V, Delgado MA, Proikas-Cezanne T, Laporte J, Deretic V. Control of autophagy initiation by phosphoinositide 3-phosphatase jumpy. EMBO J 2009;28:2244-2258.

36. Dowling JJ, Low SE, Busta AS, Feldman EL. Zebrafish MTMR14 is required for excitation-contraction coupling, developmental motor function and the regulation of autophagy. Hum Mol Genet 2010;19:2668-2681.

37. Berthon P, Duguez S, Favier FB, Amirouche A, Feasson L, Vico L, Denis C, Freyssenet D. Regulation of ubiquitin-proteasome system, caspase enzyme activities, and extracellular proteinases in rat soleus muscle in response to unloading. Pflugers Arch 2007;454:625-633.

38. Duguez S, Bihan MC, Gouttefangeas D, Feasson L, Freyssenet D. Myogenic and nonmyogenic cells differentially express proteinases, $\mathrm{Hsc} / \mathrm{Hsp} 70$, and BAG-1 during skeletal muscle regeneration. Am J Physiol Endocrinol Metab 2003;285:E206-215.

39. Fraysse B, Liantonio A, Cetrone M, Burdi R, Pierno S, Frigeri A, Pisoni M, Camerino C, De Luca A. The alteration of calcium homeostasis in adult dystrophic $\mathrm{mdx}$ muscle fibers is worsened by a chronic exercise in vivo. Neurobiol Dis 2004;17:144-154.

40. Grynkiewicz G, Poenie M, Tsien RY. A new generation of $\mathrm{Ca} 2+$ indicators with greatly improved fluorescence properties. J Biol Chem 1985;260:3440-3450.

\section{Figure Legends}

Figure 1. Phenotype of the homozygous mice at birth. A. Representative pictures of pups showing a similar morphology at birth whatever the genotype. B. Total body weight of neonates. Mean body weight of HMZ mice was $15 \%$ smaller by comparison to WT and HTZ littermate ( ${ }^{* * *} p<0.001$ using Student- $t$ test, $n=29,33$ and 16 for WT, HTZ and HMZ, respectively). C. Liver weight. The weight of the liver (mg) was normalized to the total body weight $(\mathrm{g})$. Statistical analysis using Student- $t$ test $(\mathrm{n}=29,33$ and 16 for WT, HTZ and HMZ, respectively) showed a significant hepatomegaly in HMZ mice compared to WT ( $\left.{ }^{* * *} p<0.001\right)$ and HTZ mice $(\# \# p<0.01)$. Mean HTZ liver weight was also higher when compared to WT mice $\left({ }^{* *} p<0.01\right)$. D. Blood glycemia of neonates. Glycemia was reduced in HMZ $(n=6)$ compared to WT $\left({ }^{*} p<0.05, n=10\right)$ and HTZ mice $(\# p<0.05, n=8)$ using Mann-Whitney $U$-test. Histograms in $B, C$ and $D$ represent means \pm sem.

Figure 2: Histology of liver and expression of autophagy-related genes in neonates. A. Sections $(8 \mu \mathrm{m})$ of liver from WT and HMZ mice were stained with hematoxylin and eosin (HE) and periodic acid Schiff (PAS). Images display representative fields of $4 \mathrm{WT}$ and $4 \mathrm{HMZ}$ mice. Disorganized structures were associated with glycogen accumulation. Scale bar: $20 \mu \mathrm{m}$. B. Glycogen content in liver. Glycogen content was 5-fold increased in HMZ versus WT liver ( ${ }^{* * *} p<0.001$ using Mann-Whitney U-test, $n=6$ per genotype). C. Representative LC3 and p62 immunoblots. The signal associated with the LC3-II and p62 bands was quantified by densitometry and normalized to $\alpha$-tubulin signal in WT and HMZ liver extracts. Histograms in B and C represent means \pm sem $(n=$ 6 per genotype).

Figure 3. Transcriptional analysis of dynamins and autophagy-related genes in MEF. A. Transcript levels of autophagy-related genes and the 3 classical dynamins were determined by RT-qPCR normalized to P0 expression and related to WT expression level ( $n=6$ embryos per genotype). Cells were cultured in DMEM medium containing 10\% FCS (basal) or submitted to starvation by incubation for 2 hours in HBSS (starved). ${ }^{* *} p<$ 0.01 (basal vs starved conditions in a same genotype) and \#\# $p<0.01$ (WT vs HMZ under basal conditions) using Mann-Whitney U-test. B. Representative Dnm2 immunoblot performed in 5 WT and 5 HMZ MEF cultured in basal condition or starved for 5 hours.

Figure 4. LC3-II expression level in MEF. LC3-II/GAPDH ratio was measured in WT and HMZ MEF under basal conditions or after starvation with or without Bafilomycin A1 treatment. Histograms represent the means \pm sem of 6 independent samples from 2 distinct embryos per genotype († starved vs basal conditions, * HMZ vs WT in the same condition, $\mathrm{p}<0.05$ using Mann-Whitney $U$-test). Representative LC3-II and GAPDH western-blot are illustrated below.

Figure 5. Endogenous p62-positive bodies in MEF. A. Representative p62 immunostaining in methanol-fixed cells and cultured in DMEM with 10\% FCS (Basal) or in HBSS for 2 hours (Starved) with or without Bafilomycin A1. B. p62-positive bodies were counted and histograms represent the means \pm sem (80 counted cells from 2 embryos per genotype). ${ }^{* \star \star} p<0.001$ using Student- $t$ test vs WT cells under basal conditions. Scale bar: $10 \mu \mathrm{m}$. 
Figure 6: Acidic compartments in MEF and live imaging of mCherry-GFP-p62 transfected cells. A. Representative acridine orange associated signal in MEF cultured in basal or starved medium. B. Area of acidic compartment was measured in live cells and normalized to the total cell area. Histograms represent the means \pm sem (120 counted cells from 3 embryos per genotype). ${ }^{* * *} p<0.001$ (starved vs basal in a same genotype) and ††† $\mathrm{p}<0.001$ (HMZ vs WT after starvation) using Student- $t$ test. C. mCherry (red) and GFP (green) positive bodies in WT fibroblast transfected with mCherry-GFP-p62 under basal conditions. D. Quantification of the green (GFP) and red (mCherry) dots per cell. Acidic bodies were quantified as (mCherry-GFP)/mCherry ratio under basal conditions or after starvation. Histograms represent means \pm sem. ${ }^{* \star *} p<0.001001$ (starved vs basal in a same genotype) and $\dagger p<0.05$ (HMZ vs WT after starvation) using Student- $t$ test ( $n=80$ cells from 2 embryos per genotype). Scale bar: $10 \mu \mathrm{m}$.

Figure 7: Ultrastructural features of autophagic vacuoles in MEF. Representative ultrastructure features in WT (A-C) and HMZ (D-E4) MEF. A. Early autophagic vacuole containing unaltered rough endoplasmic reticulum cisternae and ribosomes. B. Late autophagic vacuole containing diverse electron-dense degraded material. C. An example of a rarely encountered intermediate early autophagosome with a degenerated multilamellar element surrounded by intact cytoplamic content. D. Typical early autophagosome close to a late autophagic vacuole. E1E4. Different types of intermediate early autophagosomes found in HMZ MEF. They contain intact cytoplasmic material together with some electron-dense degenerated portions which may be centrally located as in $E_{1}-E_{2}$ or within the limiting membranes as in $\mathrm{E}_{3}-\mathrm{E}_{4}$. Scale bar: $200 \mathrm{~nm}$. F. Count of intermediate early autophagosomes in $48 \mathrm{WT}$ and $40 \mathrm{HMZ}$ cells from 2 distinct embryos per genotype.

Figure 8. Dnm2 sub-cellular localization in MEF. A. Western-blot analysis of Dnm2 after subcellular fractionation performed on WT and HMZ MEF under basal or starved conditions. GAPDH was used as loading control. Caveolin 1, only expressed in membrane fractions, and $\mathrm{Na} / \mathrm{K}-\mathrm{ATPase}$ mainly present in the plasma membrane fraction were used as quality control. B. Quantification of Dnm2 in plasma membrane and intracellular membrane fractions. The signal associated with Dnm2 was quantified by densitometry and normalized to GAPDH. The graph represents the means of 5 embryos per genotype \pm sem ${ }^{*} p<0.05$ using Mann-Whitney $U$ test). PM: plasma membrane. IM: intracellular membrane. Cyt: cytosol.

Figure 9. Fasting in muscle from adult HTZ mice. 4 WT and 4 HTZ adult mice of 6 months of age were submitted to 24-hour fasting. A. LC3, p62 and tubulin immunoblots in Tibialis anterior muscles from 2 WT and 2 HTZ mice. B. The graph represents the means \pm sem ( ${ }^{*} p<0.05$ using Mann-Whitney $U$-test, $\left.n=4\right)$. C and $\mathbf{D}$. Tibialis anterior ultrastructure in WT mouse. E, F, G. Tibialis anterior ultrastructure in HTZ showing an increase in autophagy-related structures. Images are representative of 2 animals per genotype. Asterisks indicate oxidative fibers where autophagic vacuoles are preferentially located. Scale bar in $E$ (also for $C)=5 \mu \mathrm{m}$. Scale bar in $G$ (also for $\mathrm{D}$ and $\mathrm{F}$ ) $=500 \mathrm{~nm}$.

Supplementary Figure 1. Tissue weights at birth. Relative to the total body weight, the mean weights of diaphragm, cardiac ventricules, brain, kidney and lung were unchanged. Number of neonates is indicated on each histogram.

Supplementary Figure 2. Liver histology during embryonic development. The hematoxylin and eosin staining is similar in WT and HMZ liver at E18.5 embryonic stages. Bars represent $100 \mu \mathrm{m}$.

Supplementary Figure 3. LC3 and p62 immunoblots and glycogen content in neonate muscles. A. Glycogen content in hindlimb muscles ( $n=5$ per genotype). B. LC3, p62 and tubulin immunoblots in hindlimb muscles from 3 animals out of 5 per genotype.

Supplementary Figure 4. p62 immunoblot and LC3-positive bodies in MEF. A. Representative LC3 immunostaining in methanol-fixed cells and cultured in DMEM with 10\% FCS (Basal) or in HBSS for 2 hours (Starved). B. LC3-positive bodies were counted and histograms represent the means \pm sem (85 counted cells from 2 embryos per genotype). ${ }^{*} p<0.05$ using Student- $t$ test vs WT cells under basal conditions. C. Representative cells transfected with GFP-LC3 expression vector and cultured in DMEM with 10\% FCS (Basal) or in HBSS for 2 hours (Starved) at 48 hours post-transfection. D. GFP-positive bodies count. Histograms represent the means \pm sem (90 counted cells from 3 embryos per genotype). ${ }^{* *} p<0.001$ using Student- $t$ test vs WT cells under basal conditions.

Supplementary Figure 5. Lysosomes and proteasome in MEF. A. Activity of proteasome and cathepsin B+L lysosomal enzymes was measured in WT and HMZ MEF using specific fluorescent probes. Histograms represent the means $\pm \operatorname{sem}(n=6$ for WT and HMZ cells, i.e. cells from 6 distinct embryos). B. Western-blot of ubiquitinated proteins in total lysates from WT and HMZ MEF. Signal was quantified by densitometry from the top of the gel to the $34 \mathrm{kDa}$ region and was normalized to the signal of actin immunoblot. The graph represents means \pm sem of 8 ubiquitinated-protein/actin ratio on MEF from 3 WT and $3 \mathrm{HMZ}$ embryos. C. Cathepsin D and pro-cathepsin D immunoblot using protein lysates from $6 \mathrm{WT}$ and $6 \mathrm{HMZ}$ cells (3 distinct embryos per genotype). Cyclin D immunoblot was performed using the same protein samples. Actin was used as loading control. D. The signal associated with each protein of interest in $\mathrm{C}$. was quantified by densitometry and normalized relative to the actin signal. Histogram represents means $\pm \operatorname{sem}(n=6)$. E. Endocytosis-induced EGF receptor degradation. 
Immunoblot. MEF were stimulated with EGF in absence (-) or presence $(+)$ of Bafilomycin A1. F. The graph represents means \pm sem of 3 EGFR/GAPDH ratio on WT and HMZ MEF.

Supplementary Figure 6. Fasting in liver from adult HTZ mice. 4 WT and 4 HTZ adult mice of 6 months of age were submitted to 24-hour fasting. A. LC3, p62 and tubulin immunoblots in liver from 2 WT and 2 HTZ mice. B. The graph represents means $\pm \operatorname{sem}(n=4)$. 

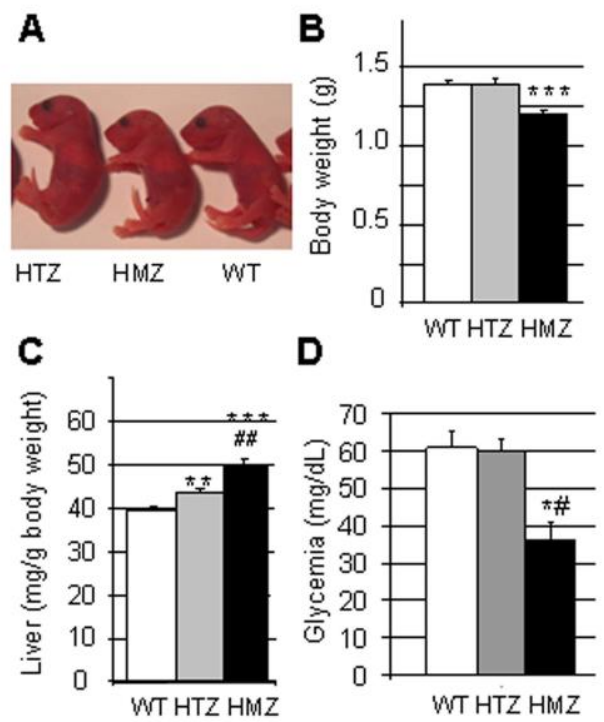

Figure 1 


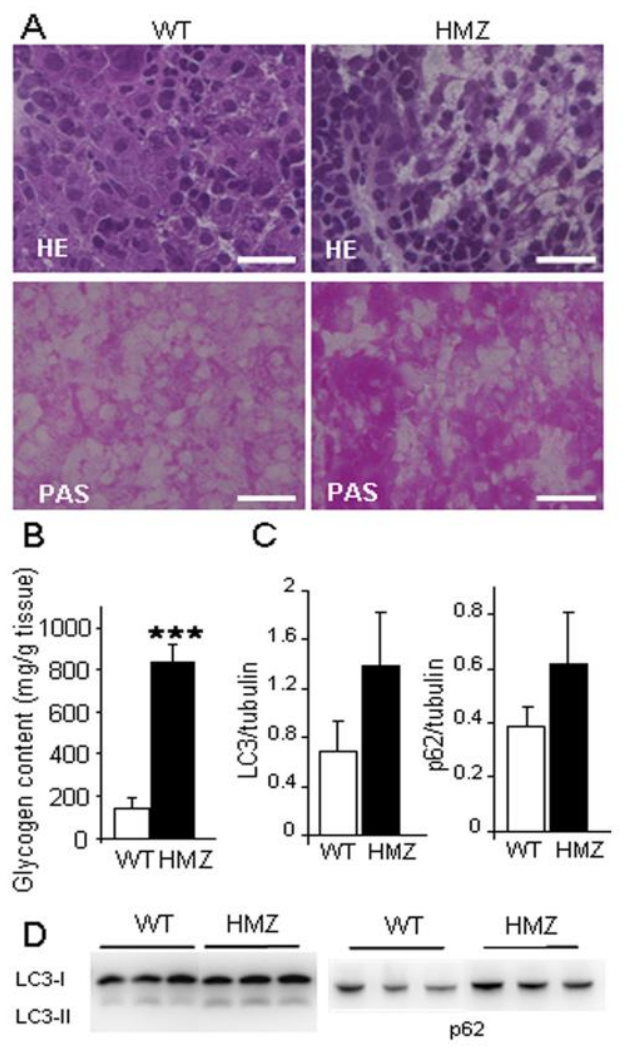

Figure 2 

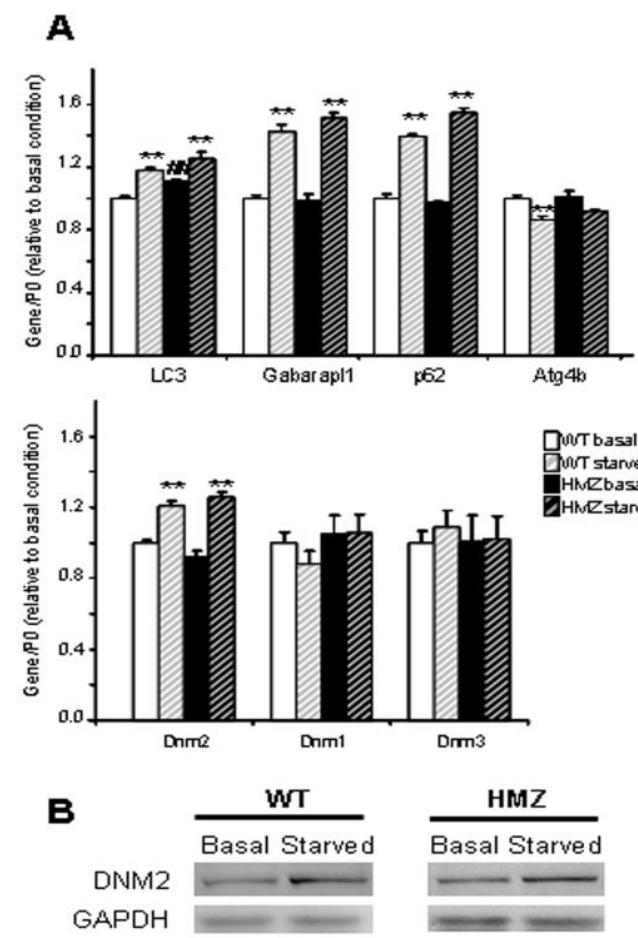

Figure 3 


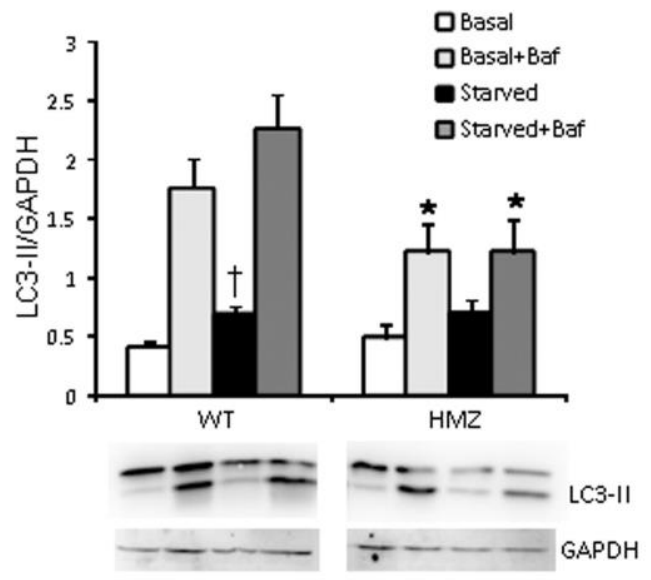

Figure 4 


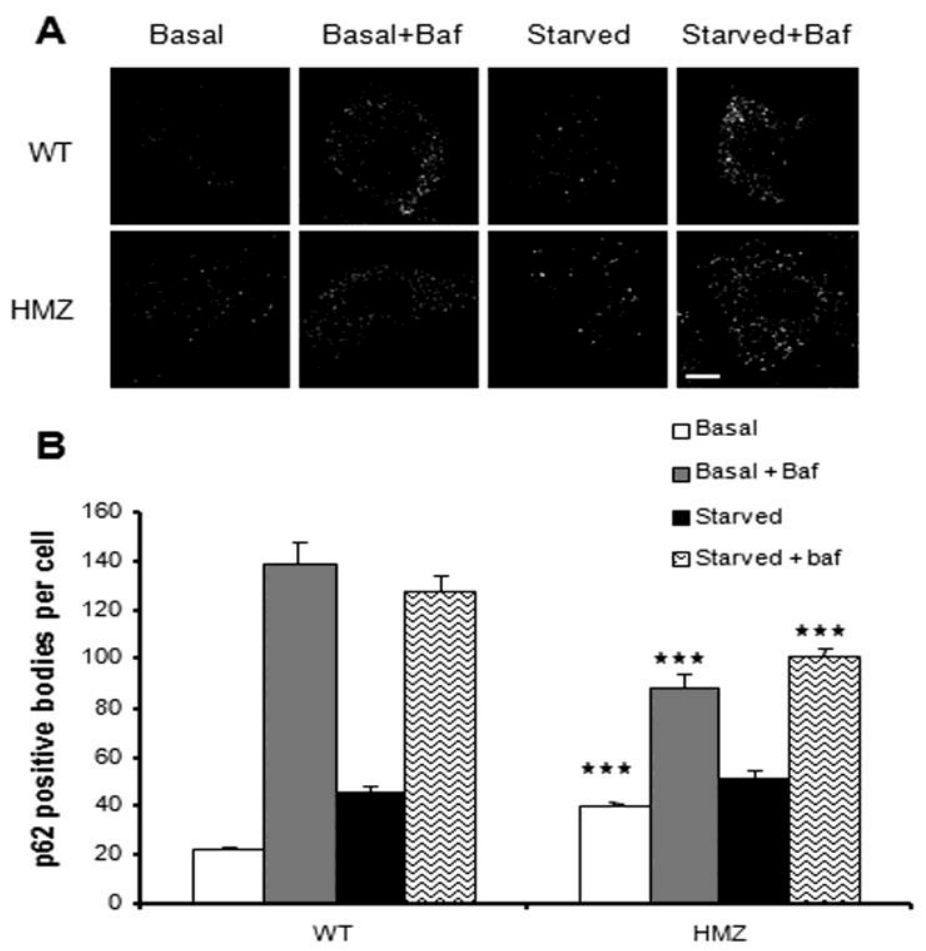

Figure 5 


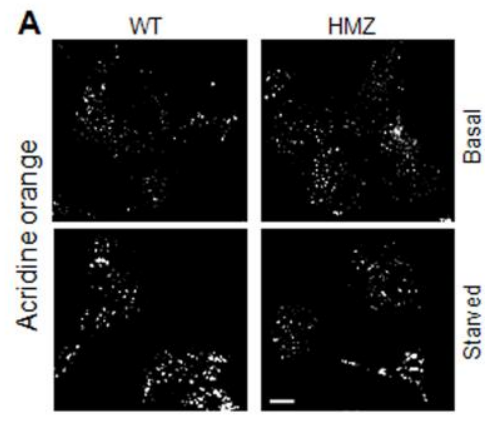

B

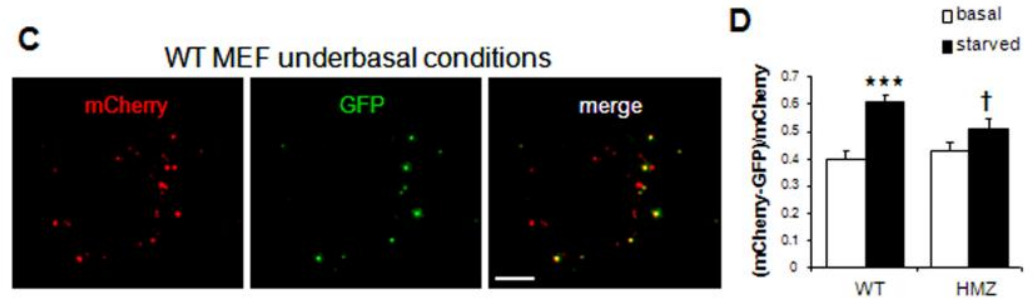

Figure 6 

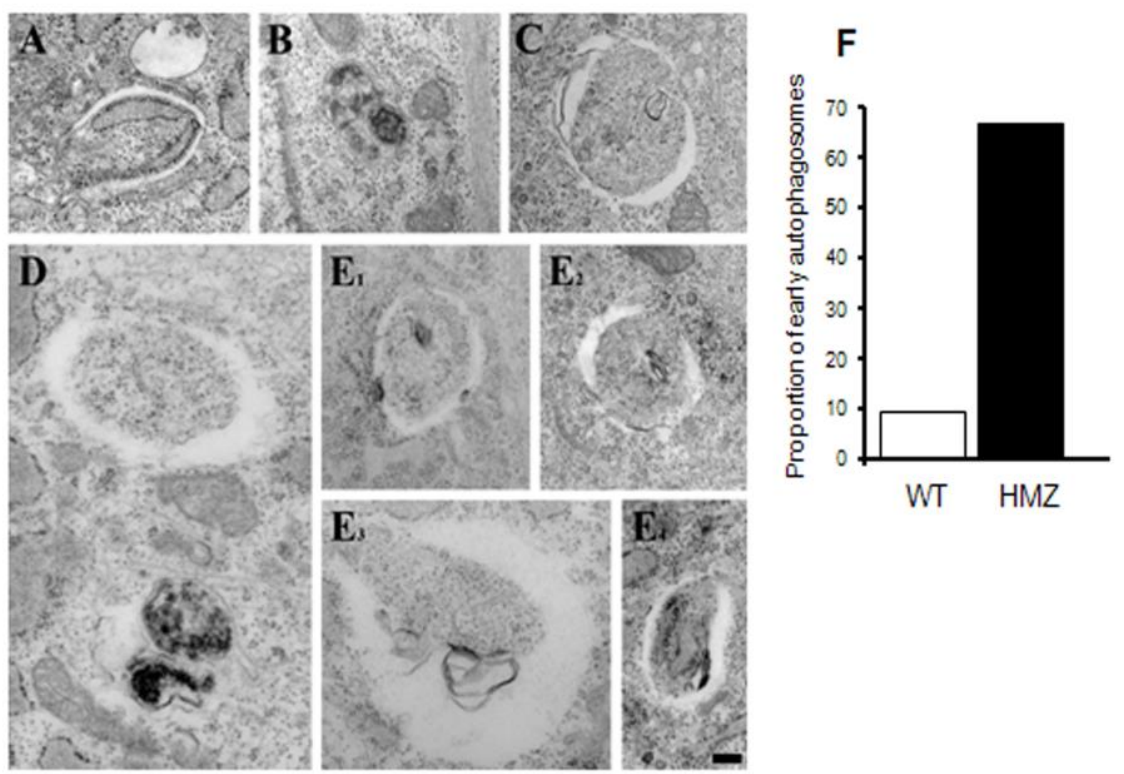

Figure 7 


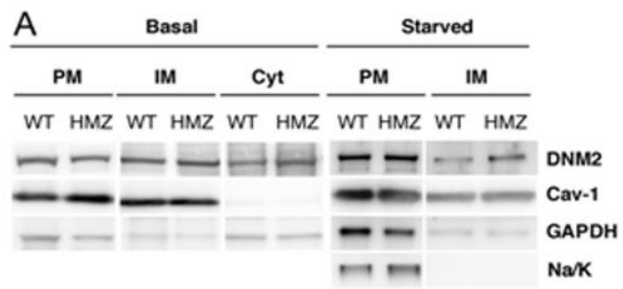

B

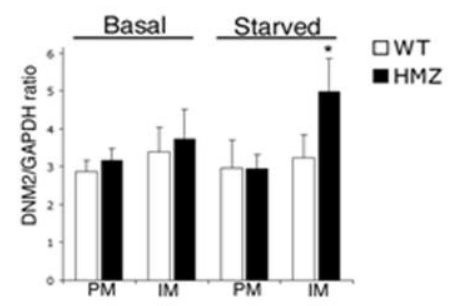

Figure 8 


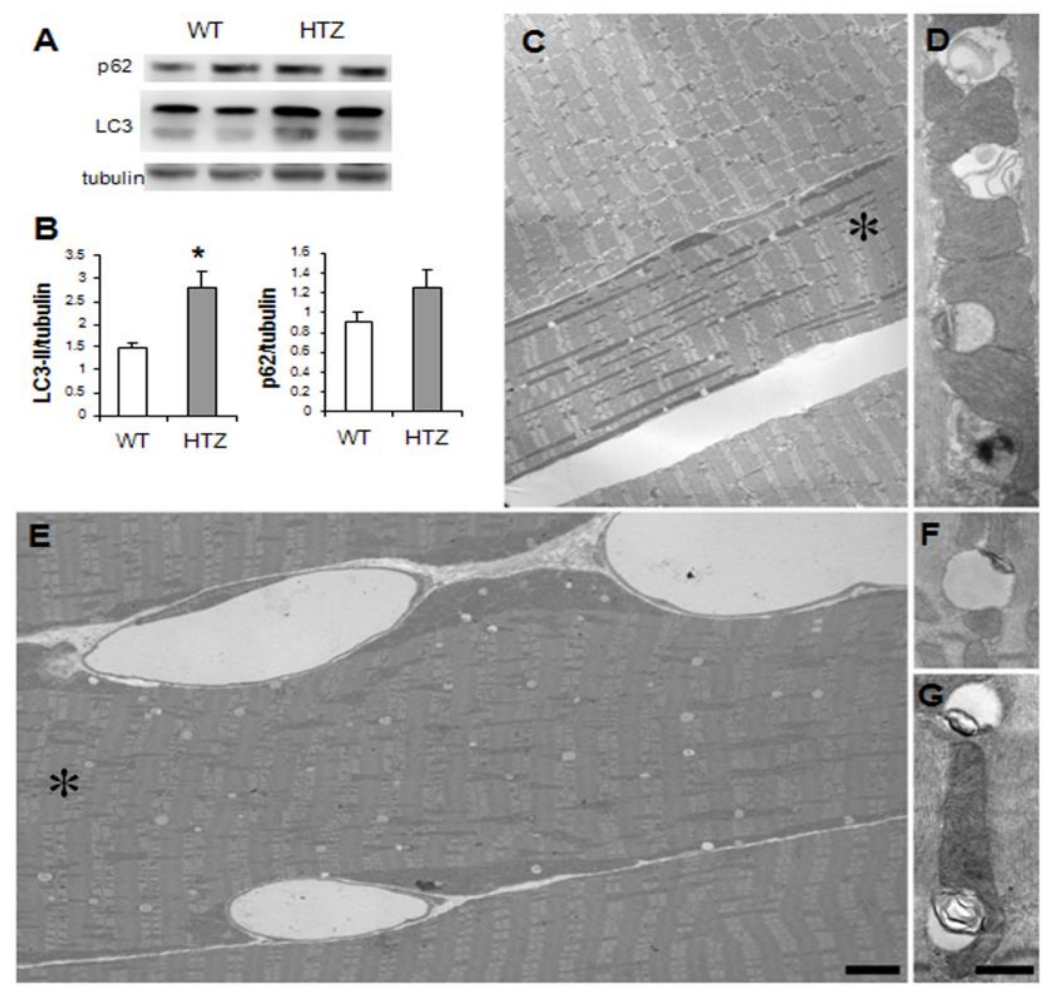

Figure 9 


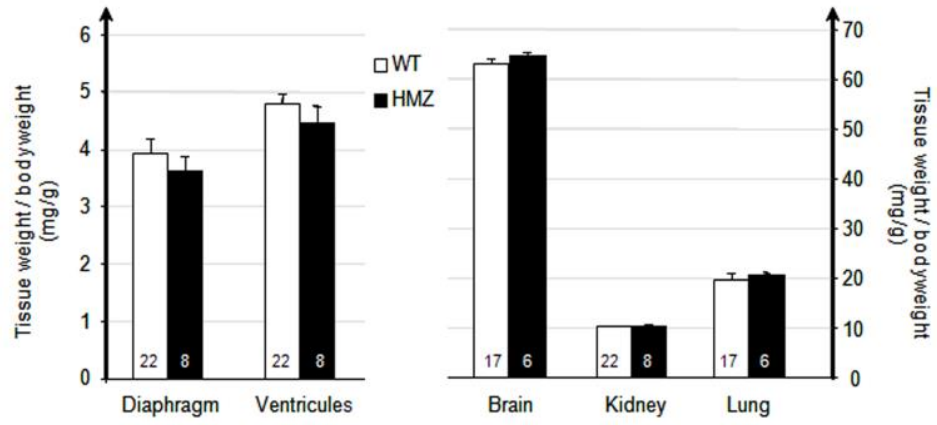

Supplementary Figure 1 


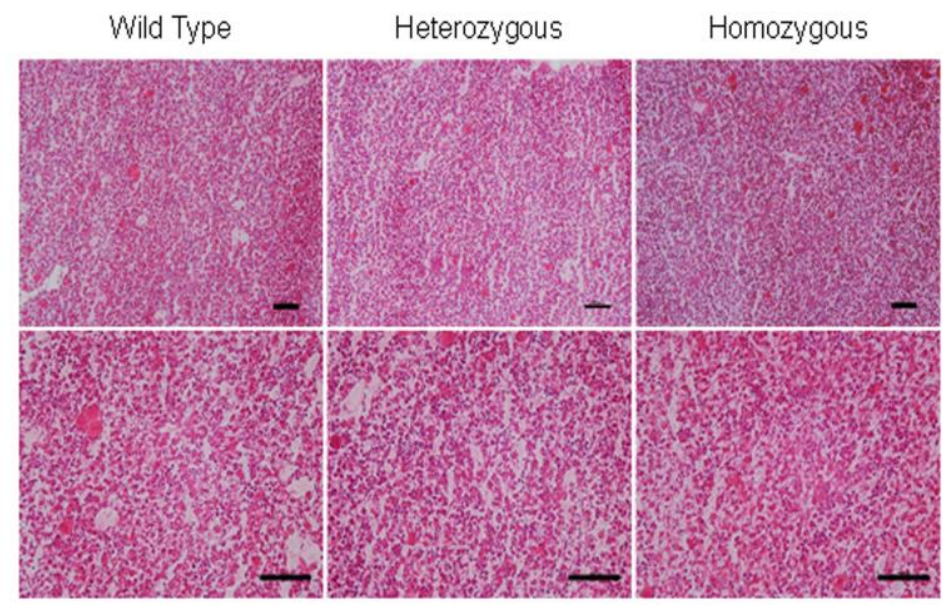

Supplementary Figure 2 

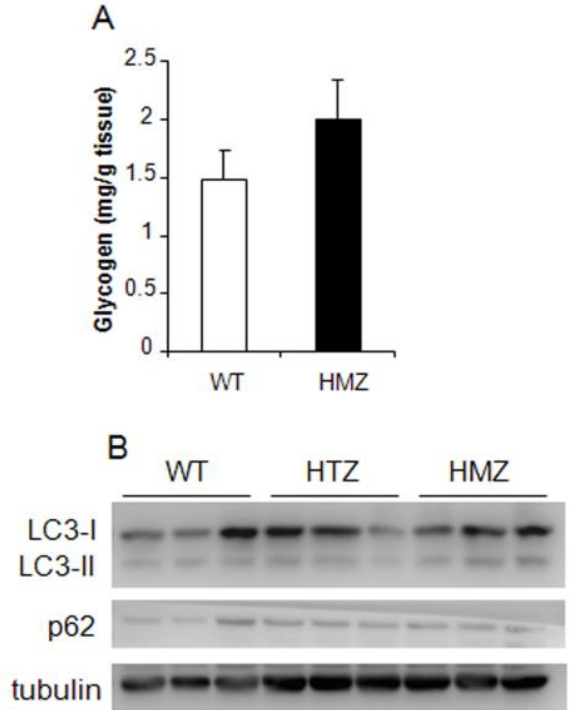

Supplementary Figure 3 

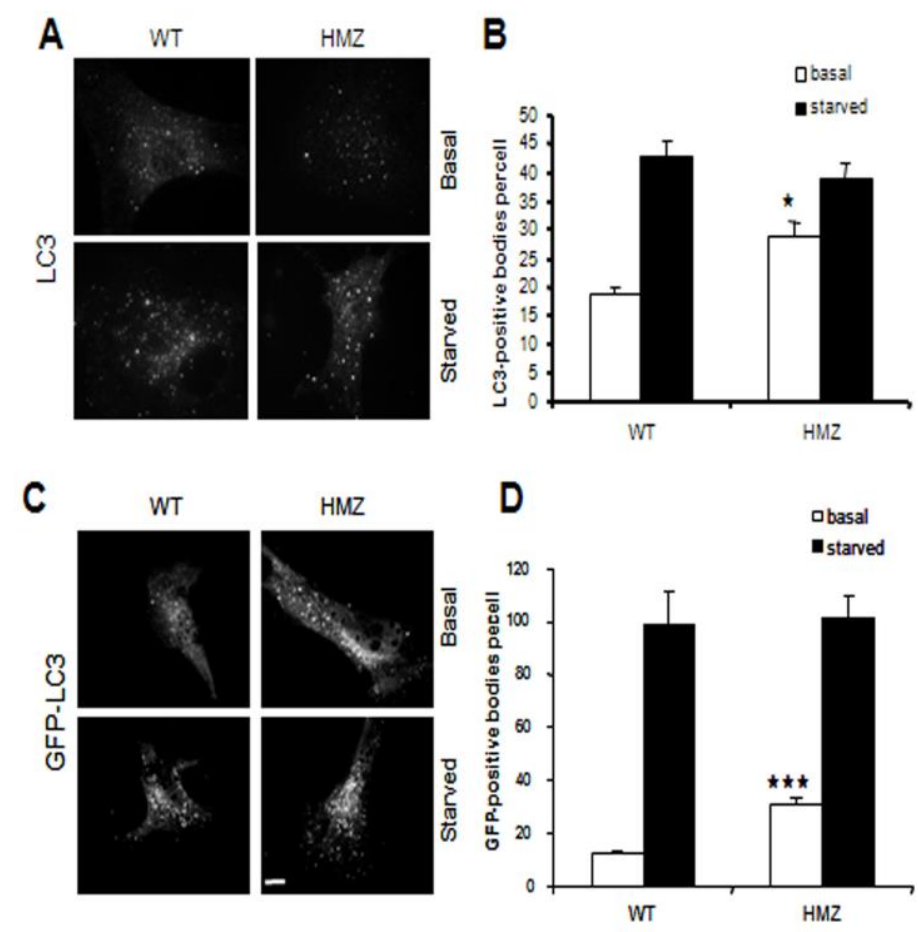

Supplementary Figure 4 
A

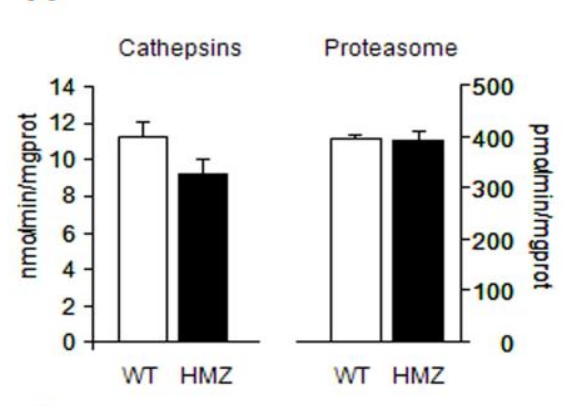

C

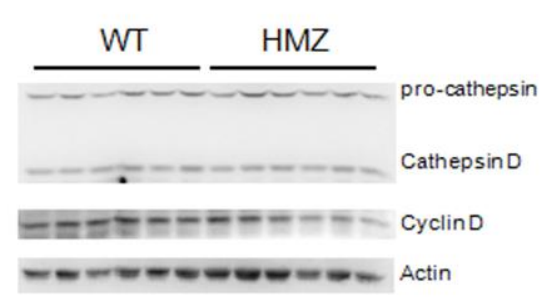

E

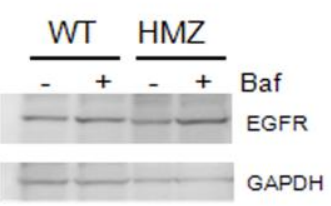

Supplementary Figure 5
B

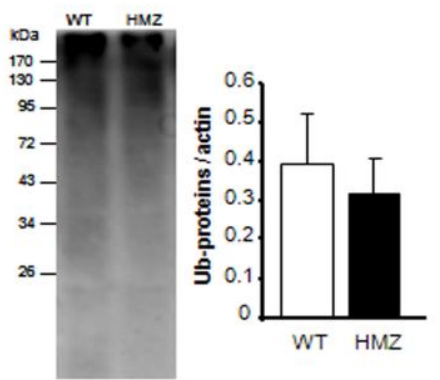

D

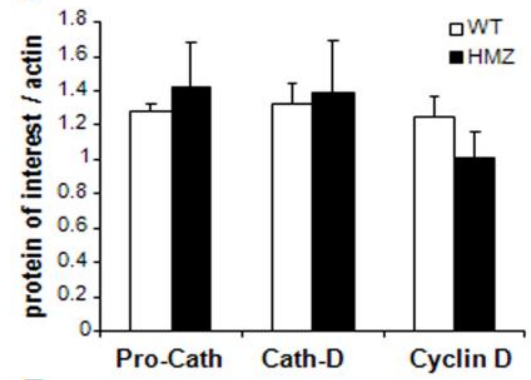

F

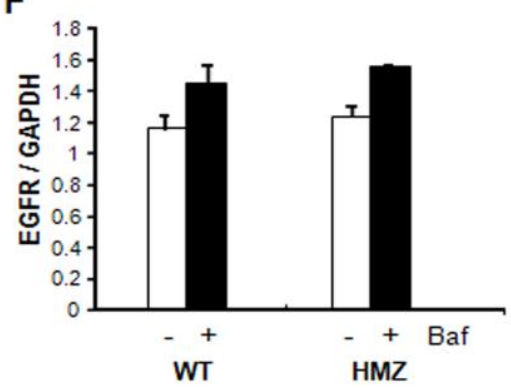


A

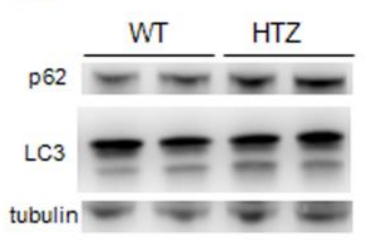

B
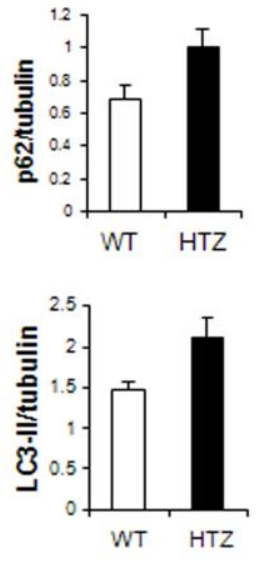

Supplementary Figure 6 
Supplementary Table 1: Sequence of primers used in the RT-PCR analysis

\begin{tabular}{|c|c|c|}
\hline Gene & Forward & Reverse \\
\hline & & \\
\hline Dnm2 & ACCCCACACTTGCAGAAAAC & GCCTTCTCAAAGTCCACTCC \\
\hline LC3b & CGTCCTGGACAAGACCAGT & ATTGCTGTCCCGAATGTCTC \\
\hline Gabarapl1 & CATCGTGGAGAAGGCTCCTA & ATACAGCTGGCCCATGGTAG \\
\hline p62 & GCTCAGGAGGAGACGATGAC & AGGGGTCTAGAGAGCTTGGC \\
\hline Atg4b & ACAGATGATCTTTGCCCAGG & TAGACTTGCCTTCGCCAACT \\
\hline P0 & CTCCAAGCAGATGCAGCAGA & ATAGCCTTGCGCATCATGGT \\
\hline
\end{tabular}

